\title{
Joven, grafiti, voz. Identidades juveniles en torno al grafiti en Guadalajaral
}

ROGELIO MARCIAL

El Colegio de Jalisco

\section{RESUMEN}

Cl grafiti se ha convertido en una manera mediante la cual se expresan una multitud de jovenes que han sido marginados por la sociedad. Este nuevo código comunicativo

tiene sus propias características, estilo y connotación. Se trata de la conquista simbólica del espacio urbano. Las autoridades y las sociedades deben estar atentas a estas manifestaciones que son síntomas de los complejos problemas que afectan a la juventud, para poder adoptar una actitud adecuada y no simplemente despreciativa y punitiva.

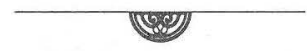

\section{ABSTRACT}

YOUNC PEOPLE, GRAFITI, VOICE. JUVENILE IDENTITIES AROUND THE GRAFITI IN GUADALAJARA

We grafiti has become a way through many marginal young people expresses their identities. This new communicative code has its own features, style and connotation. It is a matter of the symbolic conquest of the urban space. Both authorities and society must be aware of these manifestations which are symptoms of the complex problems that affect the youth, in order to be able to adopt a right attitude and not only a scorn or punishment one.

${ }^{1}$ La frase "Joven, grafiti, voz" es retomada de la canción "Grafiti" de María Eva Avilés. Aún consciente de que no es el espacio adecuado para ello, quiero dedicar desde aquí este escrito a la memoria del Dr. Francisco Moreno Parada, inagotable maestro de tantas generaciones. 

forma de expresividad popular como lo es el grafiti. Nos centramos en las elaboraciones de jóvenes en el contexto urbano de Guadalajara debido a varias cuestiones. Primero, nuestro trabajo de investigación durante los últimos cuatro años ha estado referido al fenómeno de grupos juveniles de esquina en esta ciudad, lo que nos ha llevado al estudio del grafiti elaborado por estos grupos. ${ }^{2}$ Segundo, debido a que en los últimos años ha proliferado de manera importante esta forma de expresión urbana en Guadalajara. Y tercero, porque al adentrarnos en el estudio del grafiti nos hemos dado cuenta que los grupos de esquina (conocidos como bandas juveniles) no son la única identidad juvenil que está "decorando la ciudad", contrariamente a lo que se ha pensado. Es así que lo que sigue son algunas reflexiones iniciales sobre este tema, resultantes de un primer trabajo de campo tendiente a registrar y ubicar en la ciudad algunos grafitis y de recopilar información directamente con sus creadores. ${ }^{3}$

\footnotetext{
${ }^{2}$ Actualmente soy titular en El Colegio de Jalisco de un proyecto de investigación sobre el consumo cultural de este tipo de grupos juveniles, consumo que incluye al grafiti junto con la música, el tatuaje, la vestimenta, la literatura, el sociolecto y el baile.

${ }^{3}$ Contamos con más de 150 fotografías de grafitis y 19 entrevistas informales con jóvenes grafiteros, tanto chavos-banda como taggers.
} 
Espacios y territorios: La lucha urbana por la definición de los símbolos y los significados

Hablar, antes de entender plenamente, sobre la manifestación del grafiti es difícil. El grafiti es fugaz, insolente, efímero, se modifica, agrede, se lamenta, reclama, recuerda, critica, se burla, desaparece, se generaliza, no se entiende, se sobrepone, presupone cierto conocimiento sobre política, economía, albur, la cultura callejera. Y es así precisamente porque resulta ser la expresión de aquellos para quienes la ciudad es algo más que un simple escenario muerto y estático, para quienes la adecuación de su entorno inmediato y la definición de territorios no se detiene ni siquiera por los límites que impone la propiedad privada y sus guardianes uniformados.

Pero la causa de aquella expresividad plasmada en un grafiti, tiene mucho que ver con la manera en que una sociedad abre o cierra espacios para sus diferentes sectores. En otro lugar hemos afirmado que el crecimiento urbano implica procesos de diferenciación económica y sociocultural. En cuanto al aspecto económico, la desigualdad se plasma cotidianamente en los diferentes escenarios y sectores de la ciudad, provocando muchas veces zonas elitistas con todos los servicios y otras con fuertes precariedades en donde la promesa de "vivir dignamente" no ha logrado dejar de ser un futuro inalcanzable.

En cuanto al aspecto sociocultural, la diversidad de la población se traduce en formas diferenciadas de interpretar la realidad y proyectarse hacia ella; y muchas de estas manifestaciones no encajan en los modelos, formas, canales y espacios reglamentados que la sociedad establece para la expresividad social y cultural. Sin dejar de ser válidas, estas expresiones buscan adaptar y/o crear espacios y canales en los que sea posible ubicarse, comunicarse y proyectarse hacia el resto de la sociedad; esto es, para decir: "somos nosotros y aquí estamos, a pesar de que prefieras no vernos". 
Ello convierte a la calle en un espacio idóneo para manifestar inconformidades y plasmar ideas, para "sacar" el desacuerdo a "lo público" y comunicarlo a "los otros"; creando en cada ciudad un movimiento específico de posiciones, contraposiciones, imposiciones y subordinaciones.

En el movimiento de la ciudad los intereses mercantiles se cruzan con los históricos, los estéticos y los comunicacionales. Las luchas semánticas por neutralizarse, perturbar el mensaje de los otros o cambiar su significado, y subordinar a los demás a la propia lógica, son puestas en escena de los conflictos entre las fuerzas sociales: entre el mercado, la historia, el Estado, la publicidad, y la lucha popular por sobrevivir. ${ }^{4}$

Pero en ocasiones las formas, estilos y lenguajes en diversos mensajes, como dijimos, no encajan en los parámetros oficiales de expresividad cultural y social; en muchas ocasiones porque sus creadores no pretenden ingresar a estos espacios reglamentados de expresión y reinventan códigos comunicativos con la intención de manifestar ideas pero guardar el anonimato, además de asegurarse con ello que el mensaje llegará a quien tiene que leerlo sin que otros descifren su significado. Aquí es donde surge el grafiti como un medio de expresión popular, entre algunos otros, formando parte del lenguaje urbano que define a una ciudad.

El grafiti se muestra al ciudadano, a la vez que éste responde con su mirada, en un corto circuito de contacto visual que si deja un residuo simbólico, éste no podría ser otro que una contribución a la definición de la categoría sociolectal de lo urbano. La ciudad también se define por las imágenes exhibicionistas que se muestran desde los muros, paredes y otros objetos de sus territorios. ${ }^{5}$

${ }^{4}$ Néstor García Canclini. Culturas híbridas. Estrategias para entrar y salir de la modernidad, México: Grijalbo-Conacuita (colección Los Noventa núm. 50), p. 280.

s Armando Silva. "Grafiti: punto de vista ciudadano", en Néstor García Canclini (comp.). Cultura y pospolítica. El debate sobre la modernidad en América Latina, México: Conaculta, 1991, pp. 229. 


\section{El grafiti: comunicación alternativa en el escenario urbano}

En esta definición de lo urbano, la comunicación en la vida cotidiana de quienes habitan la ciudad puede estar inscrita en diversos entornos y fluir a través de distintos medios. Sin embargo, para algunos grupos la vida urbana se vive en la calle, teniendo con ello acceso a otras fuentes de información en ocasiones más certeras que los llamados medios masivos de comunicación. Es un hecho que aquella comunicación que fluye en la vida cotidiana y los espacios públicos puede igualar en su efectividad, y en ocasiones superar, a la de los llamados medios masivos de comunicación, sobre todo en lo que respecta a la conformación de diferentes significados sobre la realidad. ${ }^{6}$

De esta forma, y entre otros medios de expresión, el grafiti maneja información sobre la realidad urbana, política y social; sintetizándola mediante mensajes directos, a través de lenguajes callejeros y en espacios propicios para su apropiación anónima. Por todo ello el grafiti se convierte, en muchas ocasiones, en el único camino para la expresión por fuera de las instituciones sociales y sus aparatos de control. Es, como afirma García Canclini, un género "impuro" o "híbrido" de expresión cultural.

El grafiti es un medio sincrético y transcultural [...] Es un modo marginal, desinstitucionalizado, effmero, de asumir las nuevas relaciones entre lo privado y lo público, entre la vida cotidiana y la política. ${ }^{7}$

En diversos grafitis llegan a quedar plasmados mensajes que al leerse con cuidado nos pueden enseñar que detrás de la idea que se maneja, está construida una forma específica de concebir la rea-

\footnotetext{
${ }^{6}$ Rossana Reguillo. En la calle otra vez. Las bandas: identidad urbana y usos de la comunicación, Guadalajara: ITESO, 1991, p. 241.

${ }^{7}$ García Canclini, op. cit., p. 316.
} 
lidad. Muchos de estos mensajes quedan referidos como una denuncia, que al ser realizada tal vez hubiese querido ser un fuerte grito de inconformidad.

Así, algunos mensajes logran ser sumamente elocuentes. Excelentes muestras de ello se vieron por muchos años en el ahora derribado Muro de Berlín; en tantas bardas usadas por movimientos de resistencia civil y guerrilla urbana como en Irlanda del Norte, Sudáfrica, el País Vasco, Centro y Sudamérica; además de un sinnúmero de muros decorados por las minorías étnicas en los Estados Unidos (negros, mexicanos, portorriqueños, salvadoreños, asiáticos).

Pero también existen otros tantos mensajes más cotidianos que no necesariamente implican la toma de posiciones políticas de índole militante. Por ejemplo, en una barda de la ciudad de México se lee el desencanto: "Estoy acostumbrándome a tu ausencia, con la dulce ilusión de olvidarte", a lo que le contestaron anárquicamente al lado: "Pues yo no me acostumbro a nada". Otro mensaje en un muro de la ciudad de Guadalajara advierte no sin reclamo: "Sí soy drogadicto y consumo todo tipo de droga, pero la peor droga que me das es tu rechazo y tu indiferencia. Gracias por ayudar a drogarme". En otra barda tapatía ubicada en la zona afectada por las explosiones del alcantarillado sucedidas el 22 de abril de 1992, se quiere recordar cotidianamente lo súbito de la tragedia: "Aquella mañana despertamos sin saber que ya estábamos muertos". Dentro de la Unidad Habitacional Tlatelolco, cerca de donde se levantara el edificio Nuevo León, derrumbado por el terremoto de 1985, hay una barda en donde se exige nueve años después la atención a los damnificados, haciendo burla del slogan publicitario con el cual el gobierno pretendió ver superada la tragedia: "México sigue en pie... y los tlatelolcas seguimos viviendo en tiendas de campaña". Por su parte, en una barda de Buenos Aires se anuncia sarcásticamente: "Argentina será dentro de poco el paraíso: vamos a andar todos desnudos", a lo que le agregaron con mayor sarcasmo: "¿Habrá manzanas?". Finalmente en un muro de Bogotá se recomienda 
sinceramente el aprendizaje cotidiano que oferta la calle por encima de informes oficiales y programas televisivos: "No le crea a nadie. Salga a caminar". ${ }^{8}$

En esta labor creativa, algunos jóvenes han tomado un importante papel en la decoración de sus ciudades. Pretenden transitar y disfrutar su entorno urbano de acuerdo a elaboraciones que consideran mucho más atractivas y artísticas que las imágenes urbanas con las que se topan. Toman en sus manos el derecho de ordenar y marcar los espacios públicos, al tener en cuenta que también ellos vitalizan la ciudad y no sólo aquellas autoridades que les entregan esa ciudad de acuerdo a sus intereses. Llegan a los lugares menos imaginables arriesgando la vida, con tal de que su "firma" sea apreciada por la mayor cantidad de transeúntes. Quieren evidenciar que tienen mucho por decir, a pesar de que la molestia que causan esté bien fundamentada. No le temen al castigo de la ley, pues esa ley también es selectiva.

Los sitios más inaccesibles han sido atrapados por el bombardeo de los botes de spray y las leyendas en las cuales los jóvenes refrendan sus lealtades y sus adscripciones grupales. El grafiti remite a nuevos usos de los espacios públicos que se desarrollaron con la urbanización; involucra una disputa simbólica por la definición del rostro de los espacios y su connotación legal o ilegal frecuentemente se deriva tan sólo del grupo que lo realiza. ${ }^{9}$

El grafiti, en tanto medio de expresión, comunica y define la imagen urbana. Para muchos jóvenes, tal medio resulta idóneo para volcar sus críticas y "gritar" sus inconformidades. Partiendo de lo anterior, pretendemos ahora revisar las peculiaridades de este tipo

\footnotetext{
${ }^{8}$ Los cuatro primeros ejemplos los hemos detectado personalmente, los otros dos están referidos en García Canclini, op. cit., pp. 315-316.Néstor García Canclini. Culturas híbridas. Estrategias para entrar y salir de la modernidad, México: GrijalboCONACUlTa (colección Los Noventa núm. 50), p. 280.

${ }^{9}$ José Manuel Valenzuela. Vida de barro duro. Cultura popular juvenil y grafiti, Guadalajara: Universidad de Guadalajara-El Colegio de la Frontera Norte, 1997, p. 87.
} 
de manifestaciones realizadas por jóvenes en la ciudad de Guadalajara. En este sentido, nos centramos en las creaciones de dos distintas identidades juveniles urbanas que se manifiestan en la capital tapatía. Primero revisaremos las características, códigos, estilos y lenguaje de los grafitis creados por lo que se conocen como bandẩs juveniles o chavos-banda; creaciones que no se podrían entender fuera de la cultura de barrio, la fuerte solidaridad que reproducen estos grupos y una marcada influencia de la cultura de la migración, todo ello relacionado intrínsecamente con la conquista, demarcación y defensa de territorios grupales en los ámbitos más íntimos del barrio de adscripción.

Posteriormente pondremos nuestra atención en aquellos grafitis elaborados por jóvenes taggers, ${ }^{10}$ sus códigos y lenguajes, que buscan crear una manera especifica de vitalizar y usar los espacios urbanos abiertos desde donde poder proyectarse a la sociedad global, no sin dejar de jactarse cotidianamente (en cada ocasión en la que aprecian su obra) de su habilidad para burlar vigilancias y contradecir reglamentaciones. Entre estos jóvenes, la colonia propia deja de ser el blanco de sus "bombardeos de spray", para poner la mira en los equipamientos urbanos de difícil acceso (puentes vehiculares, anuncios publicitarios, señales de tránsito, etc.), los lugares más concurridos (el centro histórico, monumentos, avenidas de carga vehicular pesada, iglesias, centrales de autobuses y ferrocarril, parques, etc.) y más vigilados (módulos de vigilancia, estaciones de bomberos y policía, estaciones del subterráneo, edificios del gobierno, etcétera).

10 La palabra tagger viene del término en inglés tag, el cual significa etiqueta o marca. Los taggers, que podría traducirse como los "etiquetadores", "marcadores" o "quienes hacen marcas", constituyen desde 1972 un importante movimiento cultural urbano en muchas ciudades de los Estados Unidos (sobre todo en Los Ángeles), y su presencia ha complejizado el fenómeno del grafiti en Guadalajara a partir de 1992. Para las características de esta cultura juvenil ver Valenzuela, op. cit., pp. 86-99; y Rogelio Marcial, Jóvenes y presencia colectiva. Introducción al estudio de las culturas juveniles del siglo XX, Zapopan: El Colegio de Jalisco, 1997, pp. 129-138. 
"Placazos" y grupos juveniles de esquina:

expresiones de una identidad juvenil urbana ${ }^{11}$

Las características que definen a las organizaciones informales de jóvenes en barrios populares (las que han sido bautizadas como "pandillas", pero que nosotros preferimos los términos de "grupos juveniles de esquina" o "grupos barriales") propician que muchos de estos jóvenes retomen símbolos, lenguajes y medios de expresión que se reproducen socialmente; pero que son readaptados según las intenciones e interpretaciones culturales de estos grupos juveniles. Es característico en estas agrupaciones juveniles la plasticidad con la que reelaboran pautas y valores sociales, creando formas alternativas de conducta y expresión con avances y retrocesos específicos. $^{12}$

A pesar de aceptar que la lógica, mensajes, lenguajes, imágenes, simbología, etc., empleados en los grafitis llegan a variar de ciudad a ciudad y de grupo a grupo; es también cierto que este medio informal de expresión es característico ya del fenómeno de grupos juveniles de esquina. El grafiti es parte integrante de las manifestaciones juveniles en contextos a veces muy diferentes, y su intención inicial es marcar la presencia territorial.

El grafiti es para los cholos de la frontera, los chavos banda de la ciudad de México, para grupos equivalentes de Buenos Aires o Caracas, una escritura territorial de la ciudad, destinada a afirmar la presencia y hasta la posesión

${ }^{11}$ La revisión de las características de grafitis elaborados por chavos-banda en Guadalajara, así como sus códigos y lenguajes, fue expuesta en Rogelio Marcial. "Grafiti: expresividad juvenil urbana", en Relaciones. Estudios de historia y sociedad núms. 65/66, Zamora: El Colegio de Michoacán, invierno/primavera de 1996, pp. 178-184. Aquí las retomamos actualizando algunas cuestiones específicas y aportando elementos para su comparación con las creaciones de jóvenes taggers.

${ }^{12}$ Ver al respecto Rogelio Marcial. Desde la esquina se domina. Grupos juveniles: identidad cultural y entorno urbano en la sociedad moderna, Zapopan: El Colegio de Jalisco, 1994, pp. 91-116. 
sobre un barrio. Las luchas por el control del espacio se establecen a través de marcas propias y modificaciones de los grafitis de otros. ${ }^{13}$

El primer fin que intenta cubrir el grafiti (o "placazo", como lo nombran sus propios creadores) es anunciar la existencia de sus actores. Este medio de expresión tiene un aspecto enunciativo, esto es, marca un territorio para anunciar la presencia de una grupalidad, la delimitación de un espacio y la posesión de un territorio.

Por otro lado, el grafiti también guarda la característica, para muchos jóvenes de grupos barriales, de constituirse como una forma de comunicación con lenguajes y códigos propios. Muchas veces estos jóvenes usan bardas para enviar mensajes de inconformidad y crítica a las autoridades y la policía, pero la mayoría de las veces los mensajes tienen como destinatario otro grupo juvenil o individuos específicos. Para ello se emplean códigos que sólo los iniciados pueden descifrar, mientras que el transeúnte común no entiende el significado de muchas de esas "rayas". Esto le ha valido al grafiti de grupos juveniles el rechazo social, ya que al no entenderse sus mensajes, simplemente se descalifica y se concibe como basura visual: "tachones, rayones, monos, garabatos", etcétera.

De la misma forma, este tipo de expresión juvenil responde a la necesidad de manifestación de millones de jóvenes de barrios populares, para quienes las oportunidades de expresión sociocultural en la mayoría de los casos son nulas. Existen miles de jóvenes que tienen mucho qué decir, pero no tienen en donde hacerlo. El grito se plasma en el muro en búsqueda de algún oído que quiera escucharlo y deja su huella en el contexto citadino, muchas veces con una actitud de choque ante quienes no comparten y entienden su lógica y significado.

${ }^{13}$ García Canclini, op. cit., p. 314. 
En principio el movimiento semántico del grafiti pretende el impacto ciudadano, busca chocar al espectador-observador, respecto a aquello que en los otros circuitos de comunicación oficial lo tienen cautivo; por esto, el registro de enunciación grafiti se propone como descautiverio de la ideología dominante. ${ }^{14}$

Finalmente, podemos decir que el valor del grafiti para miles de jóvenes radica también en que se constituye como una forma de transgresión de las normas sociales. Ante la carencia de espacios para la expresión cultural, tomar las bardas del barrio y de la ciudad por "asalto" (de manera anónima y en la clandestinidad de la noche) guarda significados de atrevimiento para sus creadores; significados que son altamente valorados entre los códigos de comportamiento y conducta que se desarrollan dentro de este tipo de grupos juveniles. ${ }^{15}$

A la imagen grafiti la acompaña el presupuesto de pervertir un orden, y de esta manera su gestalt se halla dispuesta hacia un contacto de implicaciones emotivas. El objeto grafiti es exhibicionista, pues lo acompaña un propósito provocador. ${ }^{16}$

Por estos cuatro aspectos (el papel enunciativo, el uso de códigos propios, la búsqueda de espacios de expresión y la valorización de la transgresión real y simbólica), y por algunos otros, este medio de expresión se ha arraigado en las manifestaciones juveniles de grupos de barrios populares. Para ellos, los placazos y grafitis son parte ya de su reproducción cultural, además de que es un medio natural y espontáneo que se aprende en la esquina del barrio y se realiza, reproduce y consume grupalmente. ${ }^{17}$

${ }^{14}$ Silva, op. cit., p. 227.

${ }^{15}$ Con respecto al papel de la transgresión en las expresiones culturales de grupos juveniles de esquina, entre ellas el grafiti, ver Rogelio Marcial, La banda rifa. Vida cotidiana de grupos juveniles de esquina en Zamora, Michoacán, Zamora: El Colegio de Michoacán, 1997, pp. 217-254.

${ }^{16}$ Silva, op. cit., p. 226.

${ }^{17}$ Marcial, Desde la esquina se domina.., op. cit., p. 100. 


\section{Códigos y lenguajes}

Dentro de la gran gama de creaciones sobre bardas de muchas ciudades mexicanas, resulta evidente reconocer que existe una gran variedad de estilos, calidad, claridad, imaginación, etcétera.

-Existen placazos muy simples, los cuales no tienen otra intención que dejar marcado un gusto personal. De ahí surgen grafitis con el grupo de rock favorito, la autopropaganda individual o la "morra" (muchacha) que quita el sueño y despierta inquietudes. De este estilos son los siguientes: Metallica, The Rolling Stones, El Tri (grupos de rock), El Compa es su Mero Machín ("El Compa" se autocalifica como el mejor del barrio), $R$ con $A$ (alguien cuyo nombre o apodo empieza con "R": p. e. Rafael o "El Rana", tiene o pretende tener una relación afectiva con una chava cuyo nombre inicia con "A": p. e. Alejandra) y Sandra Contigo Forever (un anónimo que quiere todo con Sandra).

A su vez, se pueden detectar otros placazos que se han convertido en una forma de marcar territorios, anunciar presencias y lanzar o aceptar retos a enfrentamientos, que han construido estos grupos juveniles. Aquí la simbología y mensajes tienen una elaboración un poco más compleja, debido a que se busca hacer llegar el mensaje a otro(s) grupo(s) sin que nadie más lo descifre. De este estilo son los siguientes: $L a$ Consti $=R=$ (que se lee como "La Consti Rifa" y significa que ese barrio -la colonia Constitución- domina el territorio "plaqueado") o Santanas Controla (con el mismo significado), Los Sureños $=R=40$ (que se lee como "Los Sureños Rifan Cuarenta" y significa que ese grupo puede enfrentarse en contra de 40 elementos de otro grupo).

Es común que estos placazos sean creados por un grupo y tachonado por otro que a su vez deja su nombre. Ello significa que el que lo tacha no reconoce la capacidad del primero y lo está retando a un enfrentamiento. El primero debe responder al reto o aceptar la mayor capacidad del segundo. También es común en estos grafitis 
encontrar el número trece junto al nombre del grupo o barrio (en número arábigo $=13=$, romano $=X I I I=$, o en una combinación de ambos $=X 3=$ ), ya que tal número se considera cabalístico y de suerte para las vivencias a las que se enfrentan estos grupos. Puede ser también que ese número esté referido a la letra " $\mathrm{M}$ " (por ser la letra número trece en el abecedario), lo que funciona como una inicial del creador (p.e. "El Mechas"), del grupo (p.e. "Los Metaleros"), del barrio (p.e. "Miravalle") o de muchas otras cosas (p.e. "mariguana"). En ocasiones se le agregan las letras $c / s$, que se lee "con safos", y que advierte que no se debe tachar ese placazo a menos que quien lo haga sea capaz de enfrentar al grupo que lo realizó; o 4'ever, que significa forever y hace alusión al permanente control del territorio.

Existen otros placazos mucho más elaborados y que sólo unos pocos logran descifrarlos. El ordenamiento de las partes del mensaje es alterado de acuerdo a quien lo ejecute o a la posibilidad de que sea descifrado por quienes no se pretende que lo entiendan. En otras ocasiones se suman otras abreviaturas y depende su acomodo del espacio físico del muro o poste donde se pinte. Un ejemplo es el siguiente:

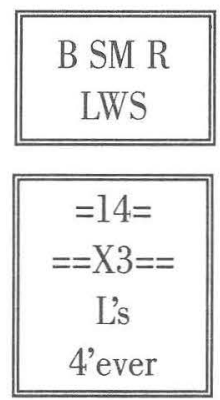

En este ejemplo las letras del primer renglón anuncian el barrio de origen y su control: "Barrio Santa Margarita Rifa". Las letras del segundo renglón representan el nombre abreviado del grupo juvenil que realizó el grafiti: "Lilwats". El número catorce que corresponde a la letra "N" y significa "Norte", la zona de la ciudad en 
donde se encuentra ese barrio. Se acompaña por el trece como número cabalístico. Finalmente las últimas letras significan "Locos", que hablan de la valentía, el peligro y "la vida loca" de los integrantes del grupo juvenil que caracteriza su cotidianidad; y forever, porque siempre será así: los locos de Lilwats que dominan ese territorio en Santa Mago que rifa, y ¿quién dice que no?

Otro tipo de grafiti, que puede considerarse más artístico porque incluye dibujos y composiciones visuales, busca retratar algunas de las creencias y vivencias más significativas para el grupo que lo elabora. Estas creencias y vivencias dejan huellas en la historia del barrio y de la grupalidad juvenil, y pueden ser imágenes de la Virgen de Guadalupe o Cristo, la valorización de símbolos prehispánicos como origen de "La Mexicanidad" o "La Raza", la muerte de un compañero en un enfrentamiento con un grupo rival o la policía, la visita a "la placa" (tutelares para menores o cárceles), las experiencias en el uso de sustancias prohibidas, la represión de "la tira" (la policía), un viaje a "Los" (Estados Unidos), etc.

"Pis", "trups", "placas" y taggers:

expresiones de otra identidad juvenil urbana

Otro tipo de grafiti que en el caso concreto de Guadalajara y su zona conurbada se ha desarrollado en los últimos años, es el llevado a cabo por jóvenes de diversos estratos sociales conocidos como taggers. Buena parte de ellos son "artistas solitarios" o pequeños grupos que nada tienen que ver con los grupos juveniles de esquina mencionados anteriormente, aunque hay grupos de taggers formados hasta con 30 elementos. A pesar de existir algunos casos, es muy común que un tagger no forme parte de un grupo barrial, la mayoría de ellos pertenecen a las clases media y alta. Estos jóvenes realizan grafitis que buscan decorar la ciudad según su propia concepción. Los temas son variados y suelen ser firmados con letras estilizadas. Cuando existen composiciones visuales, les nombran "murales". Si 
sólo es una "firma" de uno o dos colores lo llaman "trup", cuando contiene varios colores es un "pis".

A la firma se le llama "placa" al decorar espacios urbanos, como el primer cuadro de la ciudad, avenidas principales, edificios públicos, comercios, plazas, iglesias, puentes vehiculares, monumentos históricos, etc. La placa ya ensayada se plasma en pocos segundos y así se decoran muchas bardas y se evita la represión policíaca. Prepararse para "rayar" implica no sólo un gasto significativo en aerosoles (se llegan a gastar hasta 15 latas en un mural y cada lata cuesta entre 20 y 46 pesos), sino también una reserva de 100 pesos para evitar a la policía mediante una "mordida".

El grafiti de los taggers, a diferencia de los de grupos barriales, no es territorial, no marca ni delimita un territorio conquistado. Más bien se extienden por toda la ciudad, aprovechando cualquier muro sobre todo en los espacios públicos más abiertos y no limitándose al barrio de pertenencia. Por lo anterior, resulta complicado ubicar la zona de residencia de sus creadores, ya que las crews ${ }^{18}$ suelen "salir a rayar", dividiéndose las zonas de la ciudad mediante recorridos extensos. Sólo entre ellos reconocen una zona específica para cada crew.

En Guadalajara existen muchos de estos grafitis elaborados por crews de taggers o taggers solitarios como DLC (Decorando La Ciudad), AFC o 232 (Arte Fino Calle), WWS (Writing With Style), RTK (Rayando Tenemos Kontrol), PMT (Proud Mexican Tagger), MNA (MidNight Artists), PMM o 766 (Pinto Mi Mundo), SLP (Skates La Plaza), TANS (The Artist Never Stops), mVT (Mejor que Ver

${ }^{18}$ La palabra "crew" significa "cuadrilla" o "equipo" con cierto grado de organización para realizar una tarea en común. Una crew es el grupo o equipo de "taggers" al que pertenecen, el cual a diferencia de las bandas juveniles no se forma por la amistad entre jóvenes de una calle o barrio, sino entre compañeros de la escuela o de su concurrencia a ciertos lugares de recreación (conciertos, parques, pistas de patinaje, fiestas, videobares, cafeterías, deportivos, gimnasios, clubes, tianguis culturales, etc.). Al respecto ver Marcial, Jóvenes y presencia colectiva..., citado, p. 130. 
Televisión), RYP (Rayadores y Perseguidos), SC3T (Shake the Can 3 Times), DyNM (Decora y No Mueras), GRS (Grafiti-Rap-Skatos), TBK (The Boys Kulture), PCEP (Plaqueando Con Estilo Propio), TRòK (The Revolution of Kulture), KDA (Kids Different Art), KMO (Kids MultiOrder), SNE (Siempre un Nuevo Estilo), DBA (Decoración Barrial Alternativa), POW o 769 (Pinting Other World), SHD (Sector Hidalgo Decorado), $P X 5+S$ (Plaqueando Para Poder Perdurar Para Siempre), SKTX,CH, 666, 743, 782, 87, TIDER, WISK, JESH, GLS, SYXT, KDC, FCX, CRY, TAZ, SON, PLEEZ, GTO4E, NWI, BPK, MAD, DRAK, FAK, AGON, CISE, VEC, DUREN, LNAK, GREKO, OSKAR y muchos más. ${ }^{19}$

\section{Códigos y lenguajes}

Una importante característica de los taggers es el recurso de numerosos colores en una sola composición, dando la preferencia a los fluorescentes y "chillantes". Muchas de estas composiciones reproducidas en trups y pis están inspiradas en modelos elaborados en otros países. Entre ellos es común darle vida al bote de spray, caricaturizándolo y presentándolo como el responsable del grafiti. Los murales representan personajes, también caricaturizados, de individuos fuertes o diablos en actitud retadora.

Grandes placas realizadas en bardas de Guadalajara se constituyen por las iniciales de la crew o del tagger con diferentes estilos. A diferencia de los placazos de grupos juveniles de esquina en los que prolifera un alfabeto basado en letras góticas reproducido por la corriente del "cholismo", las letras de los taggers son más corpóreas, como piedras esculpidas o bloques de concreto con relleno en forma de alguna letra, conocidas como "gordas". Existe también otro tipo de letras cruzadas, conocidas como "gory-stap", que se adaptan a una línea inicial trazada a lo largo del muro, sobre la

${ }^{19}$ Marcial, "Grafiti: expresividad juvenil urbana"..., citado, p. 182. 
cual se van asentando cada una de las letras en compañía de diversas líneas que las "enredan" o "entretejen" creativamente; lo que dificulta su lectura para los no iniciados.

En ocasiones, dentro de las placas se llegan a observar números. Evidentemente, éstos no tienen los mismos significados expuestos cuando se mencionaron los códigos de los placazos de grupos barriales. Acá funcionan como claves correspondientes a las letras o iniciales de la crew o del tagger y están basados en la numeración y letras de los teléfonos digitales. Esto es, al número 1 no le corresponde ninguna letra; al número 2 le corresponden $\mathrm{A}, \mathrm{B}$ y $\mathrm{C}$; al 3 : D, E y F; al 4: G, H e I; al 5: J, K y L; al 6: M, N y O; al 7: P, R y $\mathrm{S}$; al 8: T, U y V; finalmente al 9: la W, la X y la Y (al cero no le corresponde ninguna letra porque es el número para marcar a la operadora). Así, si en una placa se ve 769 es que corresponde a la crew POW.

A pesar de no ser territoriales las placas taggers, existe entre ellos también una competencia simbólica por demostrar quién(es) es(son) el(los) mejor(es) de la ciudad. Para ello, no tachan los grafitis de otros firmando con sus siglas, sino que sobre una placa se diseña otra nueva, aprovechando ciertos trazos y colores pero cambiando totalmente la composición. De tal forma, la nueva placa cubre totalmente a la anterior y se firma para demostrar mayor creatividad. Este "atrevimiento" suele resolverse en el plano simbólico del grafiti, aunque en casos extremos también se recurre al enfrentamiento físico entre crews, como en los grupos juveniles de esquina.

Además de la calidad artística que presenta un mural o una placa, mucho de su valor radica en el espacio en el que fue realizado. El atrevimiento a decorar espacios como el primer cuadro de la ciudad, puentes vehiculares y señales de tránsito de difícil acceso, bardas de instalaciones de la policía o módulos de vigilancia, incrementan el reconocimiento de alguna crew o tagger. Pero realizar grafitis en estos espacios implica una fuerte organización y gran habilidad. Cuando es realizado por una crew, un elemento se encarga 
de dibujar el contorno de la figura caricaturizada, otro de rellenarla con color, otro de realizar el contorno de las letras o números, otro de rellenarlos y otros dos de vigilar. Cuando el grafiti lo realiza un tagger solitario, con una mano dibuja los contornos y, al mismo tiempo, con la otra (y con otro color) va rellenando los diferentes elementos de la placa. Así, los grafitis se realizan en pocos minutos, al grado de que un muro de 2 por 6 metros queda decorado en menos de tres minutos para lograr evitar la represión policíaca.

La respuesta institucional:

la "limpieza visual" por encima de la problemática juvenil

Las respuestas por parte de autoridades ante la manifestación del grafiti en diversas urbes han variado, aunque todas persiguen el mismo fin: erradicar, prohibir, desaparecer; antes de dialogar, comprender, solucionar. Para estas autoridades, lo que más preocupa es que una ciudad o colonia se vea "limpia", "aseada", "inmaculada"; sin detenerse a considerar las condiciones de exclusión social y cultural que vive un importante segmento poblacional que habita esa ciudad: la juventud.

Un caso extremo sucedido en la ciudad de Los Ángeles, California (Estados Unidos), y que es del conocimiento de muchos jóvenes grafiteros en Guadalajara, se presentó en la década pasada cuando las autoridades de esa ciudad convocaron a un gran "concurso de grafiti". Al asistir los interesados se les pidió, a manera de "currícula", que dijeran cuáles grafitis de la ciudad eran creaciones suyas. Al indicarlo, el testimonio fue grabado y después se les levantó juicio penal por daños en propiedad ajena a los pretendidos concursantes. Evidentemente el "concurso" nunca se realizó.

En las ciudades de México, Monterrey y Morelia se ha pretendido "competir" en contra de quienes decoran las paredes, repintando los muros y demás espacios afectados con acelerado entusiasmo. Para quienes realizaron esos grafitis implica un sentimiento de 
frustración por perder sus creaciones, pero muchos otros jóvenes realizan nuevos grafitis, con mayor entusiasmo y rapidez que las autoridades, al considerar esas bardas como pizarrones recién borrados y listos para volver a ser utilizados.

También ha existido el camino de la represión mediante multas y castigos a quienes se sorprenda en esta actividad, como se intentó en Guadalajara con el gobierno priísta. La respuesta de los jóvenes grafiteros ante la represión ${ }^{20}$ ha ocasionado que el grafiti se reproduzca aún más, sobre todo a partir de 1992, cuando se intensifican las campañas del gobierno municipal.

La administración tapatía actual del gobierno panista, intentó enfrentar el fenómeno partiendo de la idea de que la represión no era el mejor camino. A través del programa "Guadalajara Joven", se llevó a cabo la adecuación de bardas en deportivos de colonias populares para la realización de grafitis y la convocatoria a un "Concurso de Grafiti". Como parte de una estrategia masiva, al ayuntamiento de Guadalajara se le unió el de Tonalá (municipio conurbado a Guadalajara), con el concurso "Tonalá Rifa", y el coNALEP (instituto oficial de educación media), con otro concurso de

${ }^{20}$ Cabe mencionar que la represión, evidentemente, no se limitó a las multas. Varios testimonios de jóvenes grafiteros hablan de una represión brutal por parte de la policía en los momentos en los que eran detenidos; al grado de golpearlos, pintarles sus partes nobles con las mismas latas de "spray", obligarlos a tragarse las válvulas de estas latas e, inclusive, introducírselas por las fosas nasales (testimonios recogidos durante nuestro trabajo de campo).

${ }^{21}$ La proliferación del grafiti juvenil ante la represión policíaca en Guadalajara es mencionado en Reguillo, op. cit., p. 119; y Rossana Reguillo, "Un grito en la pared", en diario Siglo 21, Guadalajara, 24 de febrero de 1995. En cuanto a la campaña represiva municipal, ver María A. Flores, "Necesidad de manifestarse, razón de los "Graffiti”, en diario El Occidental, Guadalajara, 28 de enero de 1995; Macrina Paredes, "Con represión no dejarán de tapizar de leyendas", en diario El Occidental, Guadalajara, 28 de enero de 1995; y Sara Cuéllar, "Un lenguaje en cuestión", en diario Siglo 21, Guadalajara, 23 de febrero de 1995. 
grafiti dentro de la "Feria Cultural CONALEP 96" ${ }^{22}$ Sin embargo, la carencia de un diálogo directo con los jóvenes, la desconfianza natural de miles de ellos ante la autoridad que anteriormente reprimió, la mala organización del evento y las exigencias de que se comprometieran a no pintar en otros espacios que no sean los autorizados por el ayuntamiento, además de que pintaran sólo "cosas bonitas y positivas"; no dieron los resultados esperados por los organizadores, resultados que se enfocaron al imperativo de desaparecer el grafiti. ${ }^{23}$

A pesar de estas actividades, que pudieron ser los inicios de una campaña a largo plazo para enfrentar la manifestación de una problemática compleja que tiene su origen en un prolongado periodo de desatención de las necesidades de miles de jóvenes, la zona metropolitana de Guadalajara sigue presentando en su paisaje urbano una fuerte invasión del grafiti.

Muchos juicios sobre estas expresiones reproducen una actitud descalificativa y poco tolerante que no pretende detenerse a comprenderlas, al grado de adelantar una serie de estigmatizaciones como la siguiente.

La otrora Perla Tapatía, representada antes por una hermosa morena de largas trenzas y negros ojazos, hoy está convertida en una chica "banda" llena de tatuajes. ${ }^{24}$

Por lo anterior, las autoridades tapatías han endurecido las acciones en contra de los jóvenes grafiteros. Después de considerar

\footnotetext{
${ }^{22}$ Ver al respecto "Prestarán 500 bardas para hacer graffiti", en diario Siglo 21 , Guadalajara, 8 de noviembre de 1995; y Mario Hernández, "Convocan a bandas juveniles a certamen de Grafiti en las bardas de Guadalajara", en diario El Occidental, Guadalajara, 8 de noviembre de 1995.

${ }^{23}$ El ayuntamiento de Guadalajara a través de su Oficial Mayor de Desarrollo Social, Javier Soto Varela, reconoció el fracaso del programa diseñado para acabar con el grafiti. Ver al respecto "Habrá acciones severas contra los grafiteros", en diario El Informador, Guadalajara, 13 de julio de 1996.

${ }^{24}$ José Aguilera, "Saturada de 'grafitti' la ciudad", en diario El Occidental, Guadalajara, 6 de mayo de 1996.
} 
que la represión no era el camino, se regresa a ella mediante la imposición de multas de mil pesos para los adultos que sean sorprendidos en estas actividades; el control de la venta de aerosoles a través de la prohibición para los menores de edad y el registro de los datos del comprador justificando el empleo de la pintura; mientras que para los jóvenes detenidos se prevén castigos absurdos y humillantes.

Como primeros acuerdos, [se proponen] penas especiales a los menores de edad, como serían cortarles el pelo tipo militar y obligarlos mediante policías, a que hagan faenas de limpieza en sus respectivas colonias, a fin de exponerlos a la vergüenza pública. ${ }^{25}$

Este cambio de actitud, motivado además por el fracaso de las campañas oficiales, responde a la urgente necesidad de ciertos sectores de la sociedad de contar con una ciudad limpia. Para ello, se unen los esfuerzos de los ayuntamientos conurbados (Guadalajara, Zapopan, Tlaquepaque y Tonalá), de los comerciantes y empresarios tapatíos, porque se advierte

[...] que se acerca una extensa programación de eventos como el Tercer Encuentro Internacional del Mariachi [...], las Fiestas de Octubre y luego los festejos navideños, ante los cuales es necesario que jóvenes y adultos manifiesten su cordialidad, su amistad y su hospitalidad a infinidad de personas que visitarán nuestra ciudad. ${ }^{26}$

Sin embargo, las normas represivas pronto fueron cuestionadas por la sociedad civil de Jalisco, advirtiendo que ante todo estaban

25 "Proponen 'rapar' a los que practiquen el graffiti", en diario El Occidental, Guadalajara, 16 de julio de 1996. Para el endurecimiento de la respuesta de las autoridades, ver también "Habrá acciones severas contra los graffiteros"..., citado; "El ayuntamiento reforzará el combate a los graffit", en diario Siglo 21, Guadalajara, 16 de julio de 1996; "Proponen modificar un proyecto para controlar el graffiti", en diario El Informador, Guadalajara, 16 de julio de 1996; y "Craffiti: ¿quieres ayudarnos a combatirlo?", en diario El Informador, Guadalajara, 20 de julio de 1996.

26 "Se invita a participar en una campaña anti-graffitis", en diario El Informador, Guadalajara, 22 de julio de 1996. 
los derechos humanos de los jóvenes involucrados en el fenómeno. La Comisión Estatal de Derechos Humanos de Jalisco, según su comisionado Carlos Barba, afirmó que existían denuncias en contra de policías por "abusos de autoridad" y que, en ese sentido, dicha Comisión estaría alerta ante el accionar de los cuerpos policíacos.

La posibilidad de enfrentar el fenómeno del grafiti en Guadalajara, entonces, se reduce a un programa del Ayuntamiento tapatío que se dedica a fondear, borrar y pintar las bardas afectadas, sin trabajar directamente con los jóvenes involucrados ni replantear las políticas oficiales de atención a los problemas de la juventud. La preocupación sigue siendo la barda dañada y no el joven y sus necesidades. ${ }^{28}$

Finalmente, este tipo de acciones son vistas como poco eficaces y un sector de la sociedad, los comerciantes, exige al gobierno local medidas más severas. El argumento sigue siendo la limpieza visual de la ciudad y se propone, inclusive, tipificar al grafiti como delito y que deje de ser una falta administrativa.

La Cámara Nacional de Comercio de Guadalajara protesta enérgicamente contra los vándalos que han diseminado el cáncer llamado grafiti, y que afecta severamente la otrora limpia, decente y hospitalaria Perla de Occidente o Ciudad de las Rosas. Más por el daño que sufre la imagen de nuestra ciudad, que por lo que representa el costo de reparación de los sitios públicos y privados, la CANACO de Guadalajara rechaza tajantemente la actitud de los grupos vandálicos que se han dado a la tarea de destruir y perjudicar a la población de la zona metropolitana de Guadalajara [...] El turismo que nos visita y que es fuerte generador de divisas, es uno de los rubros en donde más

${ }^{27}$ Ver "Debe apegarse a derecho la acción contra el grafiti", en diario El Informador, Guadalajara, 29 de julio de 1996; y "Guerra, guerra contra el grafiti", en diario Siglo 21, Guadalajara, 9 de agosto de 1996.

${ }^{28}$ El Ayuntamiento de Guadalajara anuncia con orgullo que se ha trabajado sobre casi 400 mil metros cuadrados de bardas afectadas (aunque en ocasiones los tres metros de una barda cuentan como doce al ser borrados y repintados por jóvenes grafiteros en cuatro ocasiones distintas, compitiendo con la labor de las autoridades). Para este programa "anti-grafiti" ver "Lucha el Ayuntamiento contra el "Grafiti", en diario El Occidental, Guadalajara, 26 de abril de 1997. 
afecta el grafiti, ya que ante la vista de los turistas nacionales y extranjeros, la imagen que se les ofrece es sumamente desagradable [...] La Cámara de Comercio quiere impulsar [...] que se pueda tipificar como delito este cáncer. ${ }^{29}$

Es por todo lo anterior que afirmamos que los intereses detrás de la respuesta institucional están muy alejados de una preocupación con respecto a las causas que originan el grafiti. Así como esta visión no ha logrado entender los mensajes cotidianos expuestos en los muros de la ciudad, lo que no resulta necesario, parece que tampoco está interesada en ir más allá de esos muros y atender las necesidades de los miles de jóvenes involucrados en el fenómeno. El grafiti no es el problema, es la manifestación de una compleja problemática que está afectando a la juventud.

\section{Lo que queda por reflexionar detrás de los muros grafitiados}

Tal vez sea impresionante la variedad de estilos y significados que puede incluir una placa o un placazo. Sin embargo, lo más elemental no será entender el mensaje efímero del muro pintado, sino el mensaje central del fenómeno: la necesidad que impulsa a miles de niños y jóvenes de diferentes estratos sociales hacia la búsqueda por manifestar algo y expresarlo colectivamente, además de poder contar con espacios asequibles para plasmarlo y disfrutarlo cotidianamente.

La necesidad de abrir espacios de expresión juvenil se encuentra por detrás de estas manifestaciones. Las "rayas" en las paredes de nuestras ciudades deben ser leídas como los gritos desesperados de miles de niños y jóvenes, que no se identifican con las actividades y los canales de expresividad cultural vigentes en nuestras sociedades. No puede pensarse en reprimir las manifestaciones juve-

29 "Guadalajara está infestada del cáncer llamado grafitti", en diario El informador, Guadalajara, 9 de diciembre de 1997. 
niles, sancionándolas y penalizándolas, sólo porque se apartan de los modelos vigentes, incorporando formas alternativas y lenguajes propios de expresión y comunicación. Tampoco resulta adecuado abrir zonas delimitadas o disciplinarias para estas manifestaciones, planeándolo desde el escritorio, sin intentar comprender las necesidades de expresión de los jóvenes y las causas profundas del fenómeno: crisis permanente; carencias de oportunidades de trabajo, educación y expresión sociocultural; revalorizaciones y nuevos cuestionamientos individuales y colectivos de miles de adolescentes; proliferación de una idea de "ser joven" que intenta ser válida para todos los adolescentes y estigmatización para quienes no la comparten.

Ante las manifestaciones que no encajan en los códigos y canales de expresión establecidos por la sociedad, se necesita la tolerancia y la comprensión de un fenómeno mucho más complejo que la conjunción de "jovencitos holgazanes y malvivientes que no tienen nada que hacer y sólo quieren molestar, ensuciando y destruyendo la ciudad". Estos jóvenes están gritando ante oídos sordos y esos gritos quedan plasmados en los muros como huellas de necesidades insatisfechas. Se requiere capacidad para involucrarlos en procesos culturales (como sujetos actuantes y capaces de decidir los caminos) que se ajusten a sus inquietudes, que contribuyan al enriquecimiento de la creatividad y las expresiones juveniles y que les ofrezcan mejores opciones que la reproducción de conductas calificadas como "negativas" por la sociedad.

Finalmente, podemos decir que el grafiti es la conjunción de todo un lenguaje urbano que para muchos jóvenes les posibilita expresar sus particulares visiones de mundo, ante la dura realidad que viven y enfrentan cotidianamente. Es un medio de comunicación particularmente rico en códigos, lenguajes, ideas, creatividad artística, insolencia sarcástica y subversión contestataria. Para el análisis cultural seguirá siendo una excelente manera de entender la expresividad de la población civil, con todos sus posibles aciertos y contradicciones. $: 2$ 